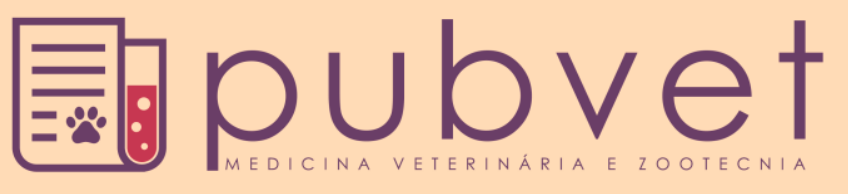

ISSN 1982-1263

https://doi.org/10.22256/pubvet.v12n4a63.1-3

\title{
Erliquiose monocítica canina: Relato de Caso
}

\section{Rones Goulart de Paula Júnior ${ }^{\ominus 1}$, Rodrigo Delbem Almeida ${ }^{\ominus 1}$, Arleana do Bom Parto Ferreira de Almeida ${ }^{\ominus 2}$, Valéria Regia Franco Sousa ${ }^{\bullet} 2$}

${ }^{I}$ Mestrando (a) em Medicina Veterinária pela Universidade Federal de Mato Grosso, Cuiabá- MT, Brasil

${ }^{2}$ Professora adjunta de Clínica Médica de Pequenos animais pela UFMT, Cuiabá-MT, Brasil.

Autor para correspondência, E-mail: rones-junior@hotmail.com

RESUMO. A erliquiose monocítica canina é uma doença infecciosa de distribuição mundial, causada pela Ehrlichia canis e transmitida pelo Rhipicephalus sanguineus, que cursa com sinais brandos a intensos ou ausência, dependendo da fase da doença. $\mathrm{O}$ diagnóstico pode ser realizado pela sorologia, pesquisa de hematozóario e técnicas moleculares, como a reação em cadeia de polimerase (PCR). O objetivo deste estudo é relatar o caso de uma cadela da raça Boxer, com 12 anos de idade, com hipertermia, taquipnéia, estridor, e petéquias, sendo submetida a exames complementares, que evidenciaram trombocitopenia, hiperproteinemia e aumento de AST e ALT; o diagnóstico foi firmado associando esses resultados com a PCR positiva para E. canis; usou-se doxiciclina para o tratamento, e após o término, o paciente retornou para nova avaliação, sendo a PCR de amostra de sangue periférico negativa. Sugere-se uma nova PCR a partir de amostras da medula óssea ou baço, pois do sangue periférico pode cursar com falsos negativos.

Palavras chave: doxiciclina, carrapato, tratamento

\section{Canine monocytic ehrlichiosis: Case report}

ABSTRACT. Canine monocytic ehrlichiosis is an infectious disease of worldwide distribution, caused by Ehrlichia canis and transmitted by Rhipicephalus sanguineus, resulting in mild to intense signs or absence, depending on the stage of the disease. The diagnosis can be made by serology, research hematozoa and molecular techniques like Polymerase chain reaction (PCR). The aim of this study is to report the case of a Bitch Boxer, 12 years old, with hyperthermia, tachypnea, stridor, and petechiae, being submitted to additional tests, that demonstrated thrombocytopenia, hyperproteinemia and increased AST and ALT; the diagnosis was established by associating these results with PCR positive for E. canis; Doxycycline was used for the treatment, and after completion, the patient returned for reassessment, being PCR negative from peripheral blood sample. We suggest a new PCR from samples of bone marrow or spleen, because from peripheral blood it may result in false negatives.

Keywords: doxycyclin, tick, treatment

\section{Erliquiosis monocítica canina: Reporte de un caso}

RESUMEN. La erliquiosis monocítica canina es una enfermedad infecciosa de distribución mundial, causada por la Ehrlichia canis y transmitida por el Rhipicephalus sanguineos, que cursa con signos débiles a intensos o ausencia, dependiendo de la fase de la enfermedad. El diagnóstico puede ser realizado por la serología, investigación de hematozoario y técnicas moleculares, como la reacción en cadena de polimerasa (PCR). El 
principal tratamiento se realiza con doxiciclina. El objetivo de este estudio es relatar el caso de una perra de la raza Boxer, con 12 años de edad, con hipertermia, taquipnea, estridor, y petequias, siendo sometida a exámenes complementarios, que evidenciaron trombocitopenia, hiperproteinemia y aumento de AST y ALT; el diagnóstico fue firmado asociando esos resultados con la PCR positiva para E. canis; se utilizó doxiciclina para el tratamiento, y después del término, el paciente retornó para nueva evaluación, siendo la PCR de muestra de sangre periférica negativa. Se sugiere una nueva PCR a partir de muestras de la médula ósea o bazo, pues de la sangre periférica puede cursar con falsos negativos.

Palabras clave: doxiciclina, garrapata, tratamiento

\section{Introdução}

A Erliquiose monocítica canina (EMC), doença infecciosa e de distribuição mundial é causada pela bactéria gram-negativa Ehrlichia canis, parasita intracelular obrigatório de células mononucleares caninas e transmitidas pelo carrapato Rhipicephalus sanguineus (Aguiar et al., 2007). A doença é caracterizada por manifestações clínicas multissistêmicas, que variam na intensidade de acordo com as fases da doença: aguda, subclínica e crônica. Os sinais clínicos mais frequentemente observados são apatia, inapetência, palidez de mucosas, febre, linfadenopatia, esplenomegalia, hemorragias e uveíte (Nakaghi et al., 2008).

A confirmação do diagnóstico se dá pela visualização de mórulas em exame de esfregaço sanguíneo nos monócitos circulantes, detecção de altos títulos de anticorpos para E. canis ou ainda pela demonstração do DNA de E. canis pela Reação em cadeia de polimerase (PCR) (Nakaghi et al., 2008).

O tratamento para esta enfermidade consiste na administração de antibióticos. As tetraciclinas podem ser utilizadas como segunda opção, mas a doxiciclina é o fármaco de eleição (Neer et al., 2002).

O presente estudo tem como objetivo relatar o caso de uma cadela, da raça Boxer, com diagnóstico para EMC firmado pela PCR e em associação aos sinais clínicos e hematológicos, assim como o tratamento com doxiciclina e acompanhamento do mesmo.

\section{Relato do caso}

No Hospital Veterinário da Universidade Federal de Mato Grosso, foi atendida uma cadela da raça Boxer, com 12 anos de idade, pesando 31 kg. Foi relatado na anamnese uma massa circunscrita na região perianal com aumento de tamanho em período de aproximadamente um ano e meio, aborto há cerca de 4 anos, EMC, controle de carrapatos com Tanidil ${ }^{\circledR}$, vacinação anti-rábica há cerca de 1 ano, sem histórico de vermifugação e acesso à rua, convivência com outro canino, e ronco frequente durante o sono.

Ao exame físico apresentou hipertermia, taquipnéia, frequência cardíaca não estabelecida, devido ao estado taquipneico associado ao estridor, petéquias na região perianal e presença de carrapatos ( $R$. sanguineus). Foi coletado sangue para realização dos exames complementares, sendo eles o hemograma completo, onde se evidenciou trombocitopenia e hiperproteinemia, bioquímico para dosagem de ureia, creatinina, AST e ALT, sendo constatado aumento de AST e ALT e a PCR positiva para Erlichia canis. Realizou-se também ultrassonografia abdominal, a qual demonstrou esplenomegalia. Diagnosticada a infecção por $E$. canis a conduta terapêutica adotada foi a administração de doxiciclina 10 $\mathrm{mg} / \mathrm{kg} / \mathrm{dia}$ via oral durante 30 dias seguidos.

Após o término do tratamento, a paciente retornou para nova avaliação; o hemograma demonstrou trombocitopenia e hiperproteinemia, o bioquímico valores normais para uréia, creatinina, albumina e ALT, e a PCR negativa para Ehrlichia canis.

\section{Discussão}

Em relação ao sexo, raça, e idade do paciente, segundo Aguiar et al. (2007) e Sousa et al. (2010) não há predisposição de EMC; porém o parasitismo por $R$. sanguineus é apontado como principal fator de risco para a EMC (Aguiar et al., 2007).

A hipertermia segundo Nakaghi et al. (2008) é frequente em cães infectados pela E. canis; a taquipnéia e o estridor segundo Riecks et al. (2007) podem ser decorrentes da síndrome das vias aéreas braquicefálicas, em cães desta raça. 
A presença de petéquias na região perianal, condiz com o descrito por Nakaghi et al. (2008), onde a trombocitopenia, evidenciada no hemograma, é clinicamente seguida pelo achado de hemorragias petequiais nas membranas, mucosas ou pele, decorrente da diminuição da meia-vida das plaquetas, resultante da sua destruição, em razão da estimulação do sistema imunológico, da cascata de coagulação e resposta inflamatória. A hiperproteinemia segundo Nakaghi et al. (2008) é um achado comum devido ao aumento das gamaglobulinas, e o aumento das enzimas AST e ALT pode decorrer de dano hepático ou do estresse sistêmico provocado pela EMC.

A esplenomegalia, segundo Nakaghi et al. (2008), se deve a replicação da E. canis em células mononucleares, principalmente no sistema fagocítico mononuclear .

A PCR para Ehrlichia canis foi positiva. Segundo Harrus et al. (2004) esta técnica pode ser utilizada para a confirmação do diagnóstico tanto na fase aguda como na crônica da infecção. O tratamento com doxiciclina, condiz com o indicado por Neer et al. (2002) que afirmam ser a droga de eleição.

Os novos exames demonstraram, trombocitopenia, contrapondo o descrito por Neer et al. (2002) e Harrus et al. (2004) que afirmam que a contagem de plaquetas aumenta com o tratamento, e hiperproteinemia, que condiz com o relatado por Harrus et al. (2004), onde a hiperglobulinemia deve regredir de forma gradativa, podendo ser necessário até um ano para a completa recuperação hematológica. A nova PCR foi negativa; segundo Harrus et al. (2004), a PCR de amostra de sangue periférico, como neste caso, é menos sensível para indicar esterilização da infecção após o tratamento, podendo resultar em falsos negativos caso a infecção persista na medula óssea ou baço, sendo amostras de ambos o mais indicado.

\section{Conclusão}

Com este relato concluímos que para o diagnóstico de EMC, é de importância o exame físico, acompanhado do histórico e de exames complementares mais sensíveis e específicos como a PCR; sugere-se que amostras de medula óssea e baço são as mais adequadas para a PCR, podendo evitar falsos negativos.

\section{Referências Bibliográficas}

Aguiar, D. M., Cavalcante, G. T., Pinter, A., Gennari, S. M., Camargo, L. M. A. \& Labruna, M. B. 2007. Prevalence of Ehrlichia canis (Rickettsiales: Anaplasmataceae) in dogs and Rhipicephalus sanguineus (Acari: Ixodidae) ticks from Brazil. Journal of Medical Entomology, 44, 126-132.

Harrus, S., Kenny, M., Miara, L., Aizenberg, I., Waner, T. \& Shaw, S. 2004. Comparison of simultaneous splenic sample PCR with blood sample PCR for diagnosis and treatment of experimental Ehrlichia canis infection. Antimicrobial Agents and Chemotherapy, 48, 4488-4490.

Nakaghi, A. C. H., Machado, R. Z., Costa, M. T., André, M. R. \& Baldani, C. D. 2008. Canine ehrlichiosis: clinical, hematological, serological and molecular aspects. Ciência Rural, 38, 766-770.

Neer, T. M., Breitschwerdt, E. B., Greene, R. T. \& Lappin, M. R. 2002. Consensus statement on ehrlichial disease of small animals from the infectious disease study group of the ACVIM. Journal of Veterinary Internal Medicine, 16, 309-315.

Riecks, T. W., Birchard, S. J. \& Stephens, J. A. 2007. Surgical correction of brachycephalic syndrome in dogs: 62 cases (1991-2004). Journal of the American Veterinary Medical Association, 230, 1324-1328.

Sousa, V. R. F., Almeida, A. d. B. P. F., Barros, L. A., Sales, K. G., Justino, C. H. S., Dalcin, L. \& Bonfim, T. C. B. 2010. Avaliação clínica e molecular de cães com erliquiose. Ciência Rural, 40, 1309-1313.

\section{Article History:}

Received 18 December 2017

Accepted 1 February 2018

Available online 21 March 2018

License information: This is an open-access article distributed under the terms of the Creative Commons Attribution License 4.0, which permits unrestricted use, distribution, and reproduction in any medium, provided the original work is properly cited. 